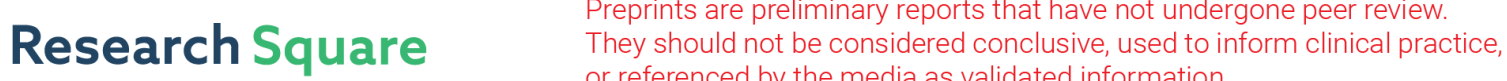 or referenced by the media as validated information. \\ Arctic Sea Ice's Amplification as a Complement to Anthropogenic Global Warming
}

Marco Morando ( $D$ marco.morando@rina.org )

RINA Consulting S.p.A.

\section{Article}

Keywords: climate change, Anthropogenic Global Warming, Atlantic Multi-decadal Oscillation, Arctic sea ice

Posted Date: May 28th, 2021

DOl: https://doi.org/10.21203/rs.3.rs-528550/v1

License: (c) (i) This work is licensed under a Creative Commons Attribution 4.0 International License. Read Full License 


\title{
Arctic Sea Ice's Amplification as a Complement to Anthropogenic Global Warming
}

\author{
Marco Morando ${ }^{1}$ \\ ${ }^{1}$ marco.morando@rina.org
}

\begin{abstract}
Climate Change is a widely debated scientific subject and Anthropogenic Global Warming is its main cause. Nevertheless, several authors have indicated solar activity and Atlantic Multi-decadal Oscillation variations may also influence Climate Change. This article considers the amplification of solar radiation's and Atlantic Multidecadal Oscillation's variations, via sea ice cover albedo feedbacks in the Arctic regions, providing a conceptual advance in the application of Arctic Amplification for modelling historical climate change. A 1-dimensional physical model, using sunspot number count and Atlantic Multi-decadal Oscillation index as inputs, can simulate the average global temperature's anomaly and the Arctic Sea Ice Extension for the past eight centuries. This model represents an innovative progress in understanding how existing studies on Arctic sea ice's albedo feedbacks can help complementing the Anthropogenic Global Warming models, thus helping to define more precise models for future climate change.
\end{abstract}

\section{Introduction}

Evidences from several scientific studies based on different proxies show the global average temperature has been far from constant in the pre-industrial era ${ }^{1}$. In addition, several sources correlate the solar activity variation to historical climate change ${ }^{2,3}$.

If a new grand solar minimum is coming ${ }^{4,5}$, it is important to understand whether the supposed future solar activity reduction could be a forcing to climate change, additional to Anthropogenic Global Warming (AGW). Indeed, being the AGW the major cause to climate change ${ }^{6}$, additional forcing could complement it, but the single variation of solar forcing is too limited to cause the climate change recorded in the last millennium; global temperature's reduction during the last grand solar minimum (Maunder Minimum) could be mainly due to volcanic activity and causes other than solar activity 6 . The oceans are Earth's heat storage body, and variations of Earth' global average temperature shall be accompanied by equivalent changes of oceans' heat content (Nuccitelli7, NASA ${ }^{8}$ and NOAA ${ }^{9}$ ), but the variation in the Oceans Heat Content (OHC), due to changes in solar energy radiation, are insufficient to justify the observed and reconstructed temperature anomalies ${ }^{6}$.

Nevertheless, positive feedback mechanisms, as the Arctic Amplification (AA), may amplify the sun-led activity led $\mathrm{OHC}$ changes. The AA increases the sun activity variations' forcing on the oceans temperatures, via changes of the Arctic sea ice extension (SIE). Increase or decrease of ice smelting changes consequently the Arctic regions' albedo, and albedo variations impact on the reflection of sun radiation, with large impacts on the Earth's overall energy balance.

According to Laubereau and Iglev ${ }^{10}$, the retreat of Arctic SIE is accompanied by enhanced solar input in the Arctic region, i.e. by a decrease of the terrestrial albedo. They studied this effect for the past six decades and estimated the corresponding global warming in the Northern Hemisphere. Their results indicate that the external forcing directly caused a temperature rise of only $0.2 \mathrm{~K}$ from 1955 to 2015 , while a notably larger effect of $0.7 \pm 0.2 \mathrm{~K}$ is found for the loss of Arctic sea ice in the same period. According to them, these numbers comprise most of the reported mean temperature rise of $1.2 \pm 0.2 \mathrm{~K}$ of the Northern Hemisphere ${ }^{10}$.

In addition, Pistone, Eisenman and Ramanathan ${ }^{11}$ state that the Arctic's albedo decrease amplifies the warming effect, revealing a striking relationship between planetary albedo and SIE, as inferred from two independent satellite instruments. They reconstructed the average global radiative forcing (RF) increase due to ice albedo effect of the Arctic ice cover from 1979 to 2011.

Other studies indicate that the Atlantic Multi-decadal Oscillation (AMO) variations may cause changes of the Arctic Atlantic sector ice cover (AASIC). The AMO index accounts for the thermal modes' variation of the North Atlantic Ocean ${ }^{12}$. The AMO is the main oceanic variation with direct impacts on the Arctic Ocean, because the Arctic Ocean is opened only to the Atlantic Ocean and is closed to other ones (it is opened only via the Bering strait to the Pacific Ocean).

A positive $\mathrm{AMO}$ index ( $\mathrm{AMO}+)$ implies a local increase of temperature in the Atlantic sector of the Arctic ocean, corresponding to a cooling in its equatorial sector and vice versa a negative one (AMO-). According to Li et al. ${ }^{13}$, over the 1979-1995 (1996-2016), years with AMO- (AMO+) correspond to above-normal (below-normal) December AASIC. This suggests that the AMO may be a second cause of the earth's albedo variation, due to its influence on AASIC (concurring with solar activity to the overall Arctic sea ice's albedo).

The AMO variations, differently from sun-led OHC changes, do not represent a net variation of Earth's heat balance, but a displacement of heat from the Southern sector (AMO-) to the Northern sector (AMO+) of the Atlantic Ocean. 
The present article provides a conceptual advance in application of AA mechanisms for modelling the historical climate change of the last millennium: the proposed 1-dimensional physical model simulates the historical global average temperature anomaly and the SIE, using as physical inputs the Sunspot Number (SSN) count, used to estimate the Total Solar Irradiation (TSI), and the AMO index historical databases.

Other articles correlate the average global temperature anomaly to SSN count or oceanic indexes, but with different, mostly mathematical approaches ${ }^{3}$. Here, we investigate the causal effect of solar activity and AMO on the average global temperature anomaly and the SIE, via AA mechanisms. This model represents an innovative progress in applying existing AA studies to quantitatively model Earth's climate change. The AA effects described in this article are complementary to the AGW effects and the proposed model could help refining the existing climate change forecasts to better adapting to climate change in the next century.

\section{Results}

A 1-dimensional physical model is used to simulate the average global temperature anomaly and SIE along nine centuries' (1200-2100). Two independent causal mechanisms are proposed: the solar activity variation, measured by the total sunspot number (SSN), and the Atlantic Multidecadal Oscillation (AMO). They are described as two independent components of forcing and their effects are summed.

\section{Determination of the first component: SIE_partial and T1}

The first component considers the effect of solar activity's variation via AA on the global average temperature anomaly. SSN count from year 1200 to 2100 from various sources 4, 5, 14, 15, 16 is used. The actual count is available only from 1700 to $2019^{14}$, but several estimations exist for the previous periods and some forecast have been published for the next decades.

A set of data for the TSI from year 1610 to 2019 is used ${ }^{17}$ and correlated with SSN count for the same period. SSN values correspond to a coefficient of correlation of 0.87 to TSI values in the period from 1610 to 2019 . Indeed, SSN count quantifies the solar activity, and a higher SSN count relates to stronger sun activity. During stronger solar activity's periods, the TSI is slightly increased, because of the balance between increased ultraviolet radiation and reduced visible radiation ${ }^{18}$.

The results of the correlation are extended, based on the SSN counts, to obtain a series of TSI data for the entire simulation period (1200 - 2100). TSI data (W/m2 of area perpendicular to the sun rays) are converted to Radiative Forcing (RF), in W/m2 of Earth's surface area.

$\mathrm{RF}$ variations have a cumulative impact on the $\mathrm{OHC}(\mathrm{OHC}$ sun). It is assumed that the RF's variations above or below its average shall lead to an increase or decrease of the $\mathrm{OHC}$ sun with respect to its average value. In Figure $1, \Sigma$ represents the year-by-year summation of RF anomalies' annual contributions to variation of OHC sun, assuming negligible black-body emission from oceans due to their temperature change ( $83 \%$ of outgoing radiation of the Earth' system is from clouds and atmosphere and oceans account for about $12 \%$, according to NASA ${ }^{19}$;

$\mathrm{OHC}$ _sun variations cause a corresponding variation of temperature of oceans' active layer (from surface to about 1,000 metres depth) and an equivalent variation of Earth's surface average global temperature anomaly. T_sun is the component of the average global temperature anomaly due only to OHC_sun variation, not the total temperature anomaly, which is determined adding the feedback.

The validation of the obtained T_sun values can be made via benchmark comparison with IPCC ${ }^{6}$ : the model's result for the period 1880 to 2010 is about $0.10^{\circ} \mathrm{C}$, which is well matching the upper side of the range estimated by IPCC $\left(0.1 \mathrm{~W} / \mathrm{m} 2 \times 0.8^{\circ} \mathrm{C} /(\mathrm{W} / \mathrm{m} 2)=0.08^{\circ} \mathrm{C}\right)$.

The AA feedback is applied to T_sun to obtain the first component of the Arctic SIE variation (delta SIE_partial) and of the average global temperature's anomaly (T1).

Studies by Laubereau and Iglev ${ }^{10}$ and Pistone et al. ${ }^{11}$ are based on a multi-decadal timeframe and consider positive feedback loops between SIE and temperature; therefore, the amplification effects estimated on temperature and SIE are not subject to further amplification effects and shall be considered as "short-term" linear amplifications in the considered multi-century timeframe of the model.

According to Laubereau and Iglev ${ }^{10}$, the average historical Arctic SIE is estimated as:

- $1955 \quad 13,400,000 \mathrm{~km}^{2}$;

- $1979 \quad 12,500,000 \mathrm{~km}^{2}$

- $2011 / 2012 \quad 11,500,000 \mathrm{~km}^{2}$;

- $2015 \quad 11,000,000 \mathrm{~km}^{2}$.

The difference between 1955 and 2015 is of 2.4 million $\mathrm{km}^{2}$. Always according to the same reference, the external forcing directly caused a temperature rise of $17 \%$ from 1955 to 2015, out of the total of the reported mean temperature rise in the Northern Hemisphere. In addition, $58.3 \%$ is due to SIE feedback amplification, and $25 \%$ due to other feedbacks. Applied to HadCRUT4 Northern Hemisphere figure ${ }^{20}$ of $0.70^{\circ} \mathrm{C}$ of total temperature anomaly for the same period (roughly equal to global temperature anomaly), it reverts to $0.12^{\circ} \mathrm{C}$ (external 
forcing), $0.41^{\circ} \mathrm{C}$ (SIE feedback amplification) and $0.18^{\circ} \mathrm{C}$ (other feedbacks). Therefore, the SIE sensitivity is estimated as $-4.86 \times 10^{-8}{ }^{\circ} \mathrm{C}$ (T_sun) per $\mathrm{km}^{2} \mathrm{SIE}$, or -20.57 million $\mathrm{km}^{2}$ SIE per ${ }^{\circ} \mathrm{C}$ (T_sun) from 1955 to 2015. According to Pistone et al. ${ }^{11}$, the SIE feedback is equal to $-2.1 \mathrm{E}-07 \mathrm{~W} / \mathrm{km}^{2}$ from 1979 to 2012 . Considering a $\lambda$ _ice of $0.80^{\circ} \mathrm{C} /(\mathrm{W} / \mathrm{m} 2)$, according to IPCC, and a variation of temperature of $0.29^{\circ} \mathrm{C}$ for the same time interval (Tokyo Climate Centre $\left.{ }^{21}\right)$, the total delta RF is $0.36 \mathrm{~W} / \mathrm{m} 2$, of which the arctic feedback represents $57.93 \%$ of the total. This result is well in line with the data from Lauenbrau and Iglev ${ }^{10}$, which report a $58.33 \%\left(0.41^{\circ} \mathrm{C} / 0.70^{\circ} \mathrm{C}\right)$ of the temperature variation. It is therefore confirmed that the two references provide a consistent set of data on Arctic Amplification feedback.

Results' robustness is further confirmed by the temperature sensitivity on RF ( $\lambda$ _ice) of $0.81^{\circ} \mathrm{C} /(\mathrm{W} / \mathrm{m} 2)$; it correlates the two independent references used and coincides with IPCC-estimated value of $0.80^{\circ} \mathrm{C} /(\mathrm{W} / \mathrm{m} 2)$. Figures obtained by correlating the data from the abovementioned sources can be summarised as illustrated in Table 1 (please refer to Methods for the correlation's full procedure):

Table 1: AA Correlation Factors

\begin{tabular}{|c|c|c|c|c|c|}
\hline Factor & Sun & Ice & $\begin{array}{c}\text { Other } \\
\text { Feedback }\end{array}$ & $\begin{array}{c}\text { Total } \\
\text { Feedback }\end{array}$ & Total \\
\hline $\mathrm{RF} / \mathrm{SIE}\left(\mathrm{Wm}^{\wedge}-2 / \mathrm{km}^{\wedge} 2\right)$ & & $\begin{array}{c}-2.10 \mathrm{E}- \\
07\end{array}$ & & & \\
\hline $\mathrm{T} / \mathrm{SIE}\left({ }^{\circ} \mathrm{C} / \mathrm{km}^{\wedge} 2\right)$ & $-4.86 \mathrm{E}-08$ & $\begin{array}{c}-1.70 \mathrm{E}- \\
07\end{array}$ & $-7.29 \mathrm{E}-08$ & $-2.43 \mathrm{E}-07$ & $\begin{array}{c}-2.92 \mathrm{E}- \\
07\end{array}$ \\
\hline$\lambda(\mathrm{T} / \mathrm{RF})\left({ }^{\circ} \mathrm{C} / \mathrm{Wm}^{\wedge}-2\right)$ & & 0.81 & & & \\
\hline
\end{tabular}

The amplification factor is $6^{\circ} \mathrm{C}$ (T_total) $/{ }^{\circ} \mathrm{C}$ (T_sun), as it can be inferred from the above table (-2.92E-07 divided by $-4.86 \mathrm{E}-08\left({ }^{\circ} \mathrm{C} / \mathrm{km}^{\wedge} 2\right)$.

In addition, it is possible to confirm the value of $-2.10 \mathrm{E}-07$ for Ice RF_feedback / SIE correlation (Wm^ $-2 / \mathrm{km}^{\wedge} 2$ $\mathrm{SIE}$ ). Considering the reduction of SIE from 1979 to 2012 of about 1 million $\mathrm{km}^{2}$, it provides a net change of 0.21 $\mathrm{W} / \mathrm{m} 2$. Considering a TSI of $1,360.83 \mathrm{~W} / \mathrm{m} 2$, the midday solar irradiation at $75^{\circ}$ latitude (where the majority of sea ice smelting is located) is estimated as $352.21 \mathrm{~W} / \mathrm{m} 2$. Considering the nights and the average angle of the sun rays during the day, the average value is $124.52 \mathrm{~W} / \mathrm{m} 2$. Neglecting cloudiness, the RF on ice-free sea can be calculated as $115.81 \mathrm{~W} / \mathrm{m} 2$ (albedo of $7 \%$ ), and RF on ice as $18.68 \mathrm{~W} / \mathrm{m} 2$ (albedo of $85 \%$ ); consequently the delta $\mathrm{RF}$ on 1 million $\mathrm{km} 2$ is estimated as $97.13 \mathrm{~W} / \mathrm{m} 2$. Reported to Earth's surface area, it provides an average global delta RF of $0.19 \mathrm{~W} / \mathrm{m} 2$, which is in line with the used value $(0.21 \mathrm{~W} / \mathrm{m} 2)$. This also provides insight concerning the causes of arctic temperature's stronger anomalies with respect to the average global temperature anomaly registered in the recent decades: the heating cause is located within the boundaries of the Arctic regions, therefore having higher impact than in the other world's regions .

\section{Determination of the second component: AASIC and T2}

The second component considers the effects of the AMO on the AASIC as concurring with solar activity to the overall Arctic albedo feedback effects. According to Li et al. ${ }^{13}$, the AMO variation is a further cause of the variation of Arctic albedo, due to its impacts on AASIC.

The Arctic Sea is extended for $15.06 \times 10^{6} \mathrm{~km}^{2}$, of which the Atlantic sector $\left(72^{\circ}-85^{\circ} \mathrm{N}, 20^{\circ} \mathrm{W}-90^{\circ} \mathrm{E}\right.$, excluding $15 \%$ of land areas) represents about the $20 \%$. The overall surface of Arctic Sea is composed by:

$\begin{array}{lll}\text { - } & \text { (1) Beaufort Sea: } & 0.92 \times 10^{6} \mathrm{~km}^{2} \\ \text { - } & \text { (2) Chukchi Sea: } & 1.25 \times 10^{6} \mathrm{~km}^{2} \\ \text { - } & \text { (3) Canada Basin: } & 0.71 \times 10^{6} \mathrm{~km}^{2} \\ \text { - } & \text { (4) Central Arctic: } & 0.45 \times 10^{6} \mathrm{~km}^{2} \\ \text { - } & \text { (5) Laptev Sea: } & 1.52 \times 10^{6} \mathrm{~km}^{2} \\ \text { - } & \text { (7) North Pole: } & 1.40 \times 10^{6} \mathrm{~km}^{2} \\ \text { - } & \text { (8) Barents Basin: } & 0.53 \times 10^{6} \mathrm{~km}^{2} \\ \text { - } & \text { (9) GIN Sea: } & 2.11 \times 10^{6} \mathrm{~km}^{2} \\ \text { - } & \text { (10) Bering sea: } & 2.17 \times 10^{6} \mathrm{~km}^{2} \\ \text { - } & \text { (11) Labrador Sea: } & 2.27 \times 10^{6} \mathrm{~km}^{2} \\ \text { - } & \text { (12) Baffin Bay: } & 0.84 \times 10^{6} \mathrm{~km}^{2} \\ \end{array}$

AMO index data from year 1585 to 2019 were selected 22,23 . For the years in the interval from 1200 to 1584 and from 2019 to 2100, no data extension is possible, due to lack of literature sources; therefore, in these intervals, the AMO value is set at its average during 1585 - 2019.

AMO+ implies a local increase of temperature of the Atlantic sector of the Arctic ocean, corresponding to a cooling of the equatorial sector of the Atlantic Ocean. AMO- implies the opposite.

According to Li et al. ${ }^{13}$, the variation of AMO index from 1975 to 2012 (increased of 0.417 ) is associated to a decrease of December AASIC of about 1.271 million km², from a maximum ice extension in 1975 of 2.40 million 
$\mathrm{km}^{2}$ to a minimum ice extension in 2012 of 1.13 million $\mathrm{km}^{2}$. The data indicate a correlation factor of -3.05 million $\mathrm{km}^{2} /$ delta $\mathrm{AMO}$ index and consequently of $0.74^{\circ} \mathrm{C} /$ delta $\mathrm{AMO}$ index (applying the factor of $-2.43 \times 10^{\wedge}-7$ ${ }^{\circ} \mathrm{C} \_$total feedback $/ \mathrm{km}^{\wedge} 2 \mathrm{SIE}$ described in the previous section).

Applying this factor to AMO provides the second component of the total anomaly of the average global Temperature (T2) and the AASIC variations.

\section{Results summary and comparison with literature benchmarks}

The two components are not alternative, but additional, and their independent effects on both global average temperature's and SIE / AASIC's anomaly are summed. After offsetting their zero value, the result of global average temperature and SIE are compared with historical data.

For the period $1200-2100$, the overall average global temperature (T) reconstruction is reported in Figure 1. Several benchmarks have been used to compare the model results. Data from 1250 to 1859 are from Spencer ${ }^{24}$ (data shifted of $+0.08^{\circ} \mathrm{C}$ to set the zero at year 1880) and from Lockwood ${ }^{25}$ (data shifted of $+0.20^{\circ} \mathrm{C}$ to set the zero at year 1880); data from 1860 to 1900 are from the Hadley Centre ${ }^{26}$ (data shifted of $+0.40^{\circ} \mathrm{C}$ intercept Tokyo Climate Centre in 1905) and since 1900 are from Tokyo Climate Centre ${ }^{21}$ (data shifted of $+0.75^{\circ} \mathrm{C}$ to set the zero at year 1880).

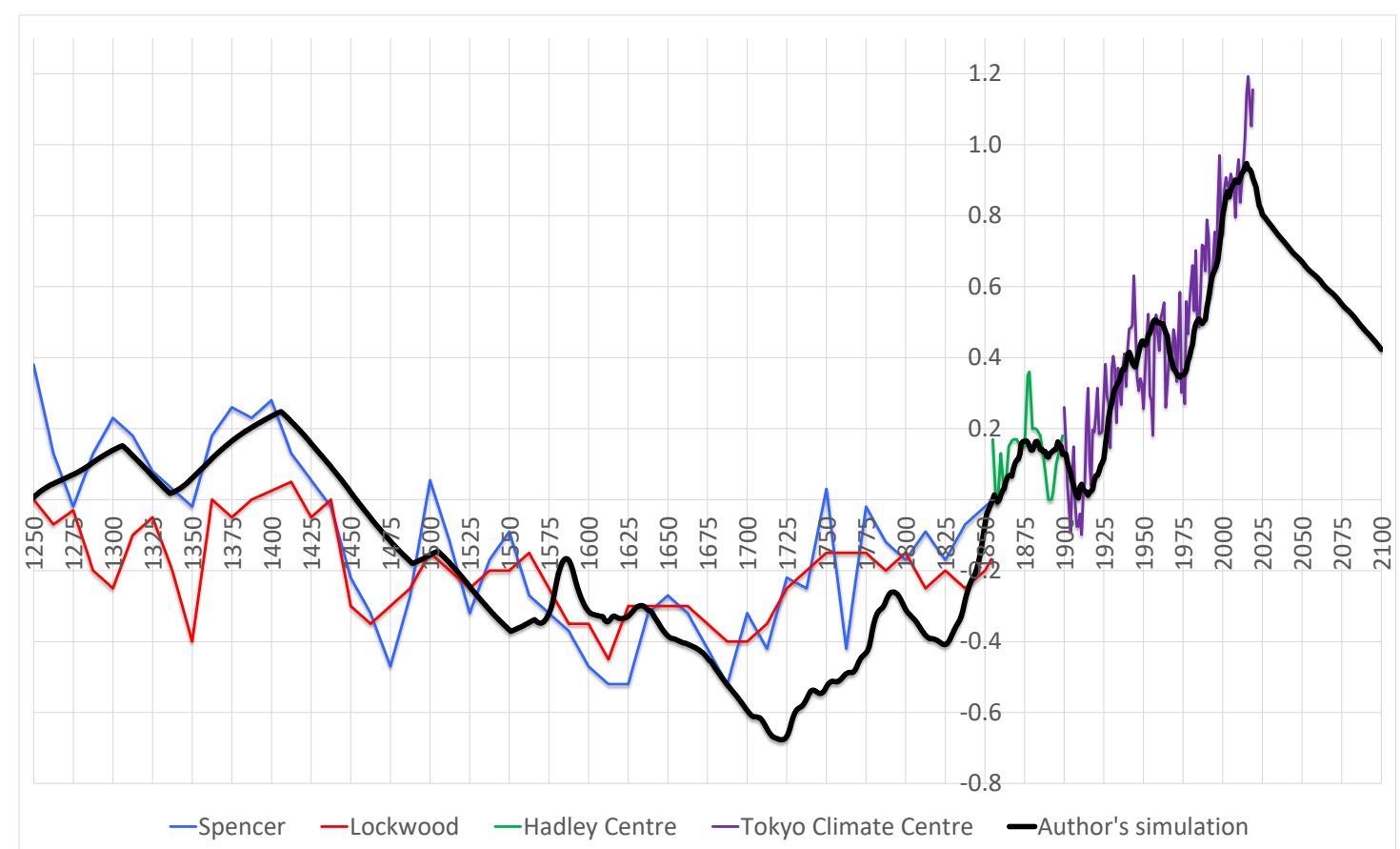

Figure 1. Author's modelled temperature anomaly vs. historical data of global average temperature anomaly for the entire data series from year 1250 to 2100 . On x-axis the date in years and on $y$-axis the average global temperature in ${ }^{\circ} \mathrm{C}$

Figure 2 details the same data of Figure 1 on the overall average global temperature (T) reconstruction but focussed to the period $1855-2019$. 


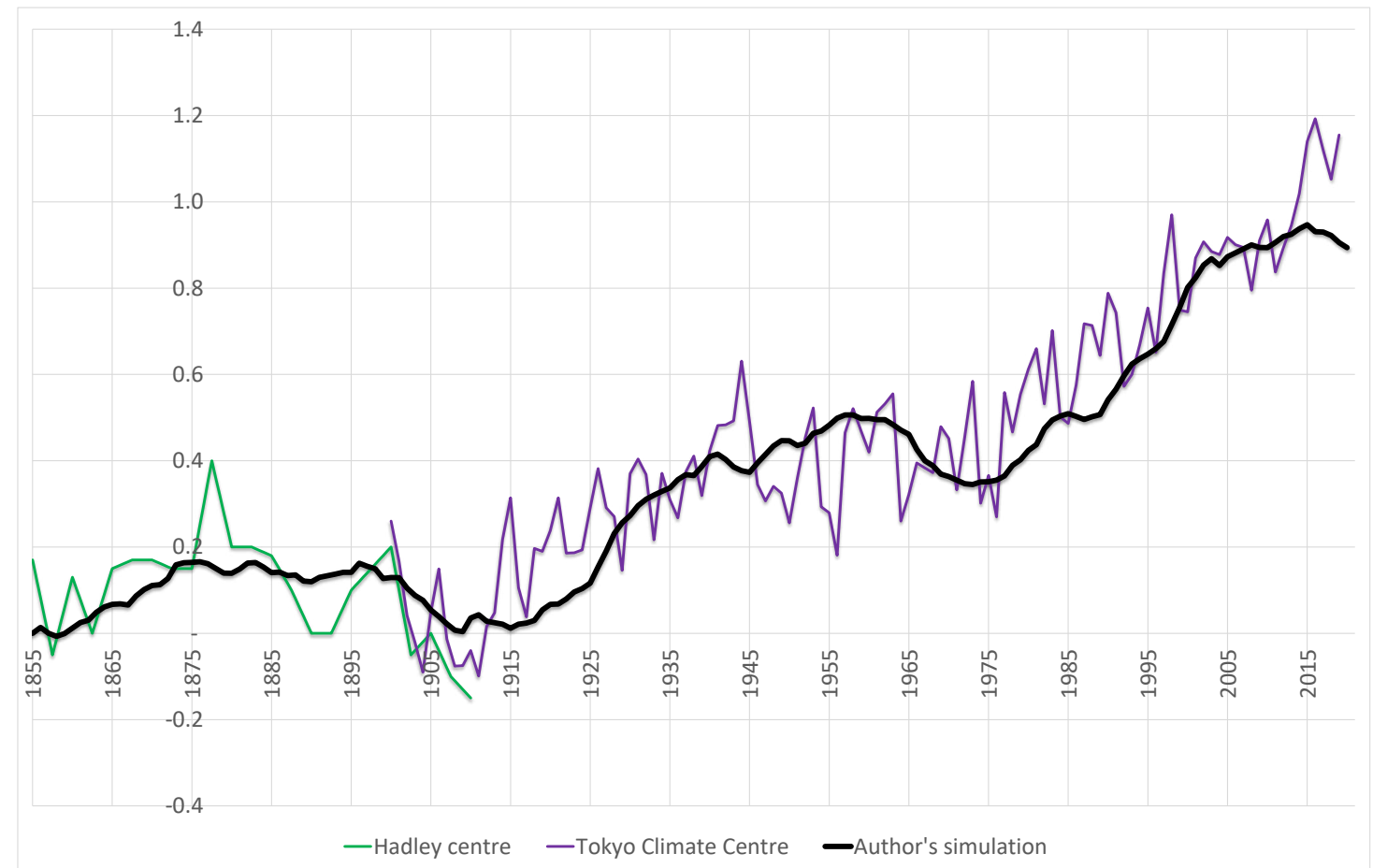

Figure 2. Author's modelled temperature anomaly vs. historical data of global average temperature anomaly for the data series from year 1855 to 2019. On x-axis the date in years and on $y$-axis the average temperature anomaly in ${ }^{\circ} \mathrm{C}$

The total SIE value on the entire data series from 1200 to 2100 is shown in Figure 3.

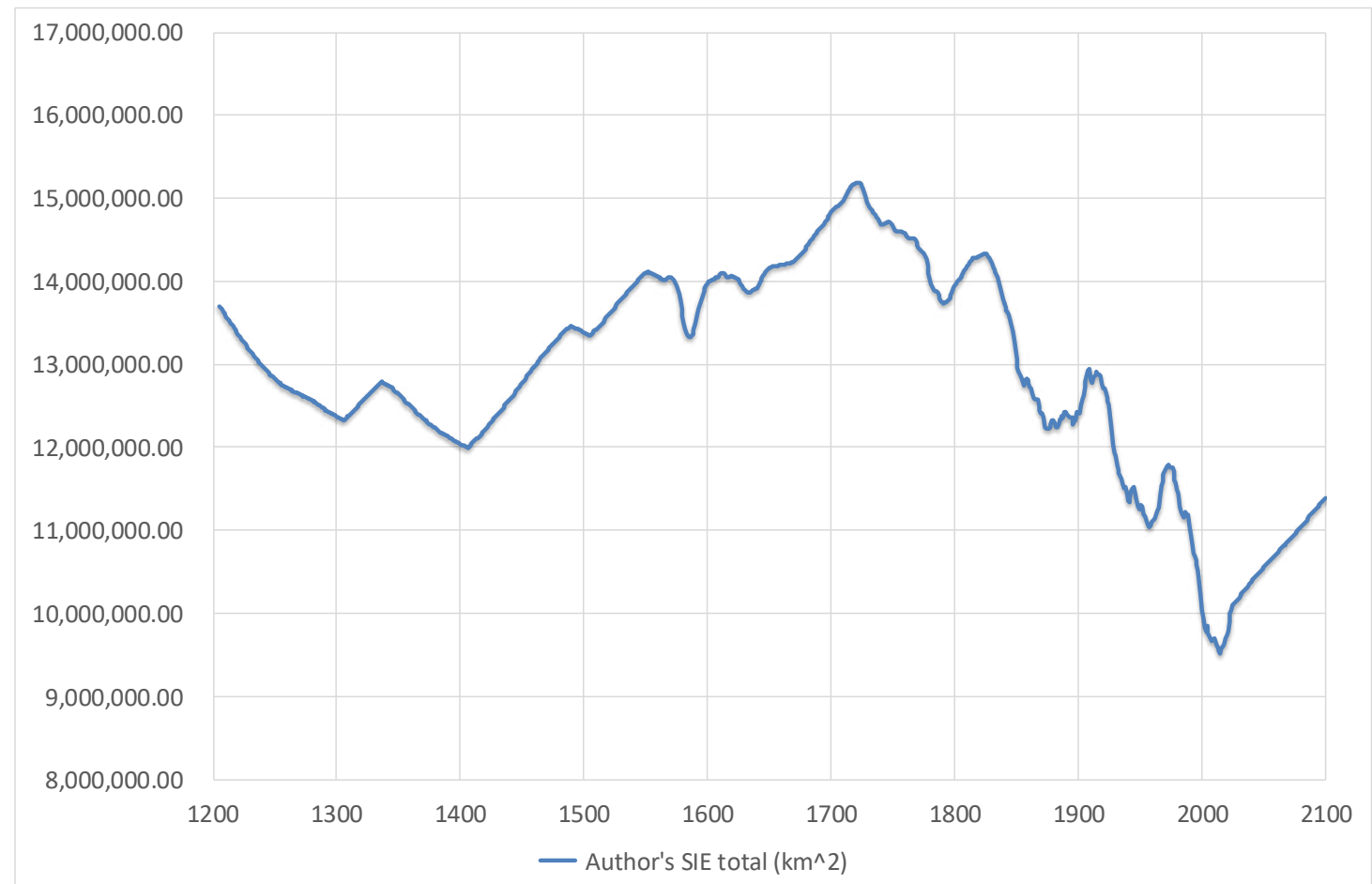

Figure 3. Dataset on SIE. On $x$-axis the date in years and on $y$-axis the SIE

Figure 4 illustrates the result for the SIE overall reconstruction for the period 1950 - 2010 and compares it with historical data from year 1950 to 2010. March SIE data are from ACSYS, AARI sea ice data27, September SIE data are from Alekseev ${ }^{28}$. 


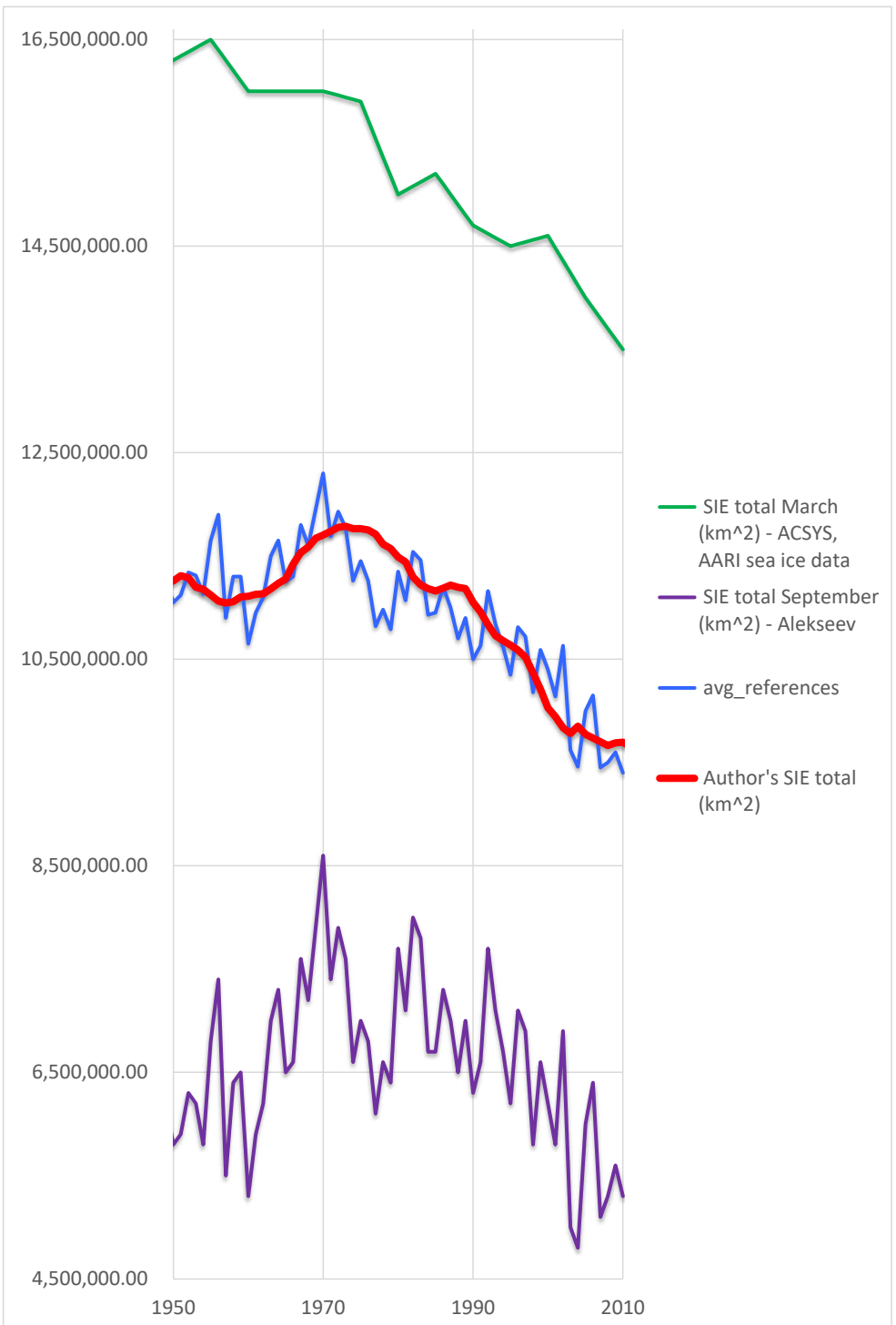

Figure 4. Author's modelled SIE vs. historical data from year 1950 to 2010 . On x-axis the date in years and on yaxis the average SIE in $\mathrm{km}^{2}$

The results show an interesting match of the model with the historical data from literature. This suggests the model could help forecasting future climate change scenarios and identifying effective paths for climate change adaptation and for increasing human climate resilience for the next decades.

\section{Discussion}

For purpose of simplicity, Anthropogenic Global Warming effects have not been included in the model, to keep it focussed on forcing due to solar activity and AMO changes. A next step should be to integrate the model in the wider framework of Anthropogenic Global Warming models and understand the combined effect of the entire forcing on climate change. This integration will be object of further studies by the author. It can be observed from Figure 2 that the model is well simulating the historically metered or reconstructed average temperature anomaly data since 1200 .

As major exceptions, we can indicate a peak in 1575 - 1600, which finds no correspondence in the benchmark data. In addition, the Maunder Minimum appears in the model to further deepen in the period $1700-1725$, contrary to historical evidence. Consequently, Dalton Minimum (1800 - 1830), is lower than historical data in absolute value, but its temperature relative decrease is well in line with historical benchmarks.

In addition, the 2016 - 2020 temperature peak is not explained by the model: instead, the Anthropogenic Global Warming well explains the peak, and this confirms that a combined model based on AGW and AA should be developed in order to account all the types of forcing on climate change.

Data from 1200 to 1250 are not shown, because the Model takes about 50 years from its first running year (1200) to get up to speed. 
The AA overall effect is considered by Laubereau and Iglev ${ }^{10}$ in the period from 1955 to 2015 , which covers a full cycle of the AMO (from maximum to minimum to new maximum, with a total zero effect); therefore, the model considers the two effects to be completely independent and sums them as two linear independent components of the forcing.

It is important to highlight that the AA effects on $\mathrm{OHC}$ sun shall cause a further variation of the $\mathrm{OHC}$ itself; nevertheless, Laubereau and Iglev ${ }^{10}$ and Pistone et al. ${ }^{11}$ studies are based on a multi-decadal timeframe and are already considering the cumulative impacts (feedback of feedback) on temperature and SIE. Therefore, the AA factor is applied to the variation of temperature due only to sun-lead oceans' heating (T_sun), linearising the problem.

Impacts of oceans' heating on the Antarctic ice extension are not considered in the model. This is because literature data on "Antarctic Amplification" are scarcely available, and the Antarctic region is expected to be less influenced than the Arctic one by OHC's changes, the Antarctic being a continent surrounded by sea and not an ocean surrounded by land.

It is important to note that reliable forecast data for SSN and AMO are not available for post 2020. This suggests the model should be updated in the future.

\section{Methods}

The physical model considers the SSN count and AMO index as input and the average temperature anomaly and SIE reconstruction as output. The 1-dimensional model is satisfactory in the sense of a Taylor expansion of the (unknown) functions $\Delta T(y)$ and $\Delta \mathrm{SIE}(\mathrm{y})$ depending on a variety of local and geographical parameters, where second and higher order terms are neglected. Retaining only the first order terms of the expansion, the problem is linearised.

\section{Step1: From SSN to TSI}

\section{Input Data}

The observed data of SSN from 1700 to 2019 are obtained from the Royal Observatory of Belgium ${ }^{14}$. Reconstructed data from 1200 to 1610 are obtained from Solanki ${ }^{15}$, where the data are adapted from Beryllium 10 data.

Data from 1610 to 1699 are obtained from $\mathrm{Eddy}^{16}$, where the data are reconstructed mainly from reported observations of the time.

Data from 2020 to 2040 and from 2041 to 2100 are respectively from estimations by Shepherd ${ }^{5}$ and Abdussamatov 4 .

Concerning Total Solar Irradiation (TSI), data are from SORCE ${ }^{17}$ for years from 1610 to 2019.

\section{Model Description}

SSN count is representative of the solar activity (of both quantitative TSI and its spectral characterisation), but the correlation is not linear. The model finds the correlation equation between SSN count and TSI for the overlapping period $(1610-2019)$. Since TSI is strongly influenced by prolonged periods of solar grand minima, two different equations have been used in function of the 11-year SSN moving average. Period of grand solar minima have been characterised by SSN counts below 40 per month for prolonged periods, as well as periods of solar maxima by SSN counts above 40 per month for prolonged periods.

$$
\begin{aligned}
& \text { if }(11 \text { years moving average } S S N<40): \operatorname{TSI}(y)=0.0041 \times \operatorname{SSN}(y)+1360.28 \\
& \text { if }(11 \text { years moving average } S S N>40): \operatorname{TSI}(y)=0.0055 \times \operatorname{SSN}(y)+1360.70
\end{aligned}
$$

Where:

- $\quad$ TSI $(y)=\quad$ TSI $(\mathrm{W} / \mathrm{m} 2)$ in the year $\mathrm{y}$

- $\quad \operatorname{SSN}(\mathrm{y})=\operatorname{SSN}$ monthly count in the year $\mathrm{y}$

- $\quad \mathrm{y}=\quad$ Considered year

The overall $R^{2}$ on the period $1610-2019$ is 0.75 , coefficient of correlation (R) is 0.87 .

\section{Model Output}

The TSI data on the entire data series from 1200 to 2100 are obtained. Unabridged data from SORCE have been used for this time interval, while the equations (1) and (2) have been used for the remaining years. 


\section{Step 2: From TSI to RF_sun}

\section{Input Data}

Input data are the modelled TSI data.

\section{Model Description}

The following equation is used:

$$
R F(y)=\frac{0.7 \times \operatorname{TSI}(y)}{4}
$$

Where:

- $\quad R F(y)=\quad$ sun Radiative Forcing in the year $y$

- $\quad T S I(y)=\quad T S I(W / m 2)$ in the year $y$

- $\quad 0.7=\quad 1-0.3$ (where 0.3 is the average Earth albedo)

- $y=\quad$ Considered year

- $4=\quad$ sphere geometrical factor

Model Output

TSI is referred to orthogonal metered sun radiation. The average value for the unit of Earth's surface area (RF) shall be obtained. The solar RF data on the entire data series from 1200 to 2100 are obtained.

\section{Step 3: From RF_sun to delta OHC_sun}

\section{Input Data}

Input data are the modelled RF_sun data.

\section{Model Description}

The difference between RF_sun (y) and its average is considered to cause of the increase / decrease of the Ocean Heat Content (OHC_sun). The rationale is that when the RF is above its average value, OHC_sun is increasing,

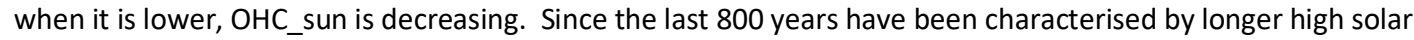
activity periods than low solar activity ones, the mathematical average is not considered as a proper indicator. Therefore, the average value considered for RF_sun is the average of its mean value for periods with SSN $<40$ (solar minima) and its mean value for periods of SSN $>40$ (solar maxima).

The RF_sun value differential to its average is multiplied by the total Earth surface to obtain the differential absolute value of received energy. Yearly energy gains / losses are summed year by year, according to below equation.

$O H C \_$sun $(y)=\sum_{n=1200}^{y}\left(\frac{\Delta R F_{- \text {sun }}(y) \times \text { Earth surface } \times 8760 \times 3.6}{10^{19}}\right)$

Where:

- $\quad$ OHC_sun $(y)=$ cumulative $\mathrm{OHC}\left(10^{22}\right.$ Joule) in the year $\mathrm{y}$

- $\quad \Delta R F \_s u n(y)=$

- $\mathrm{y}=$ differential sun $R F\left(W / m^{2}\right)$ in the year $y$

- $8760=$ Considered year

- $\quad$ Earth surface=

Model Output

The results are reported in Figure 5. 


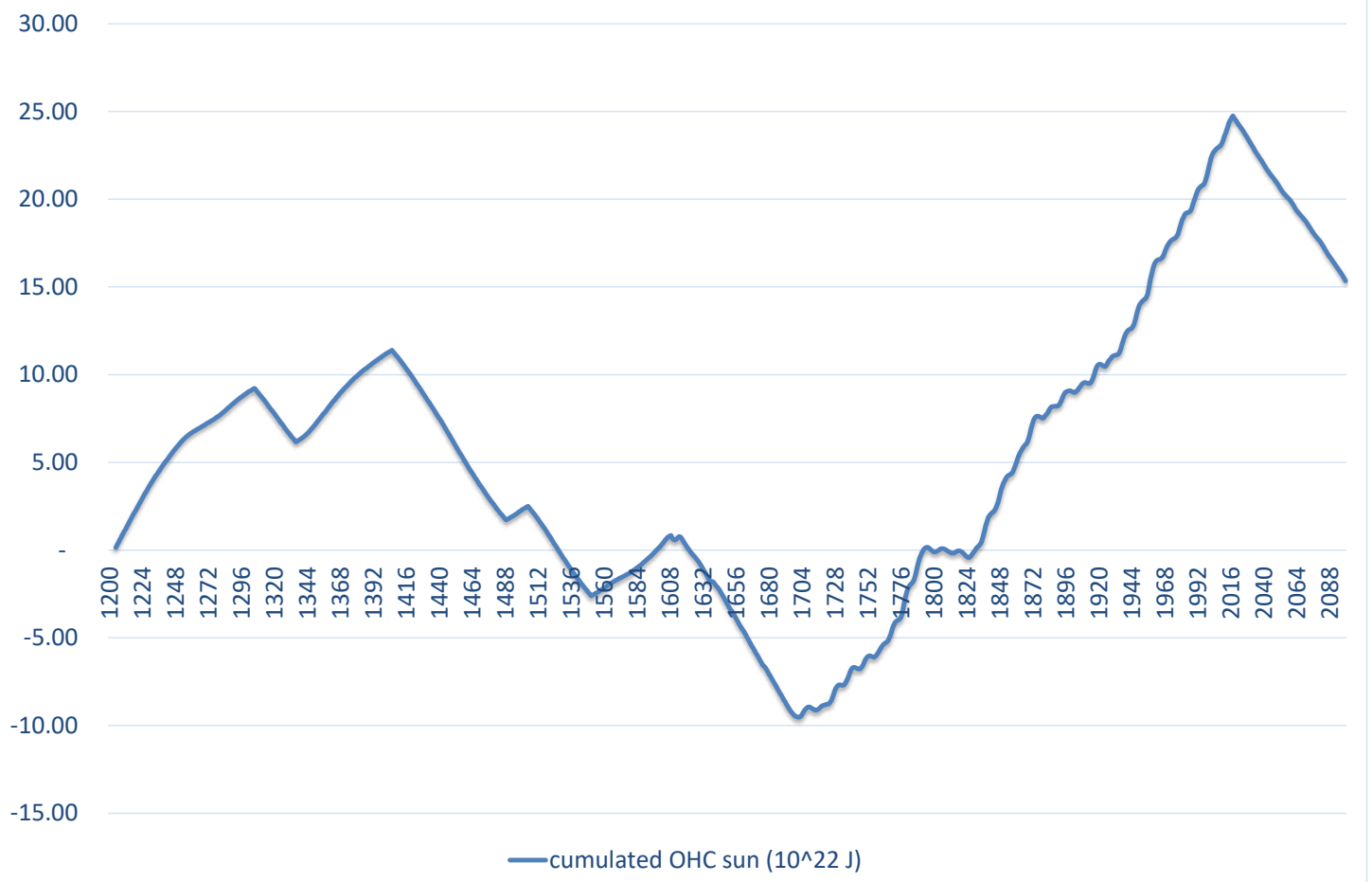

Figure 5. Dataset on Solar induced OHC_sun Variations. On $\mathrm{x}$-axis the date in years and on y-axis the OHC_sun

\section{Step 4: From delta OHC_sun to delta T_sun}

\section{Input Data}

Input data are the modelled OHC_sun.

\section{Model Description}

Considering the active layer of the oceans and the oceans' surface, the variation in oceans' temperature is obtained considering the sea water specific heat.

$T_{-}$Sun $(y)=\frac{\text { OHC_sun }(y) \times 10^{22}}{3.85 \times \text { Ocean surface } \times \text { active layer } \times 10^{6}}$

Where:

- $\quad T_{-} \operatorname{sun}(\mathrm{y})=$

- $\quad$ OHC_sun $(y)=$

- $\mathrm{y}=$

- $3.85=$

- $\quad$ ocean surface $=$

- ocean active layer=

sun-induced temperature anomaly $\left({ }^{\circ} \mathrm{C}\right)$ in the year $\mathrm{y}$ cumulated $\mathrm{OHC}\left(10^{22}\right.$ Joule) in the year $\mathrm{y}$

Considered year

Sea water specific heat $\left(\right.$ Joule $\left./\left(\operatorname{gram}^{\circ} \mathrm{C}\right)\right)$

$3.6 \times 10^{\wedge} 14 \mathrm{~m}^{2}$

about $1,000 \mathrm{~m}$

Given the overwhelmingly higher thermal inertia of the oceans with respect to the land, it is assumed to correspond to the average global temperature anomaly component caused by sun activity variations.

\section{Model Output}

The solar-induced component of global average temperature on the entire data series from 1200 to 2100 is shown in Figure 6. 


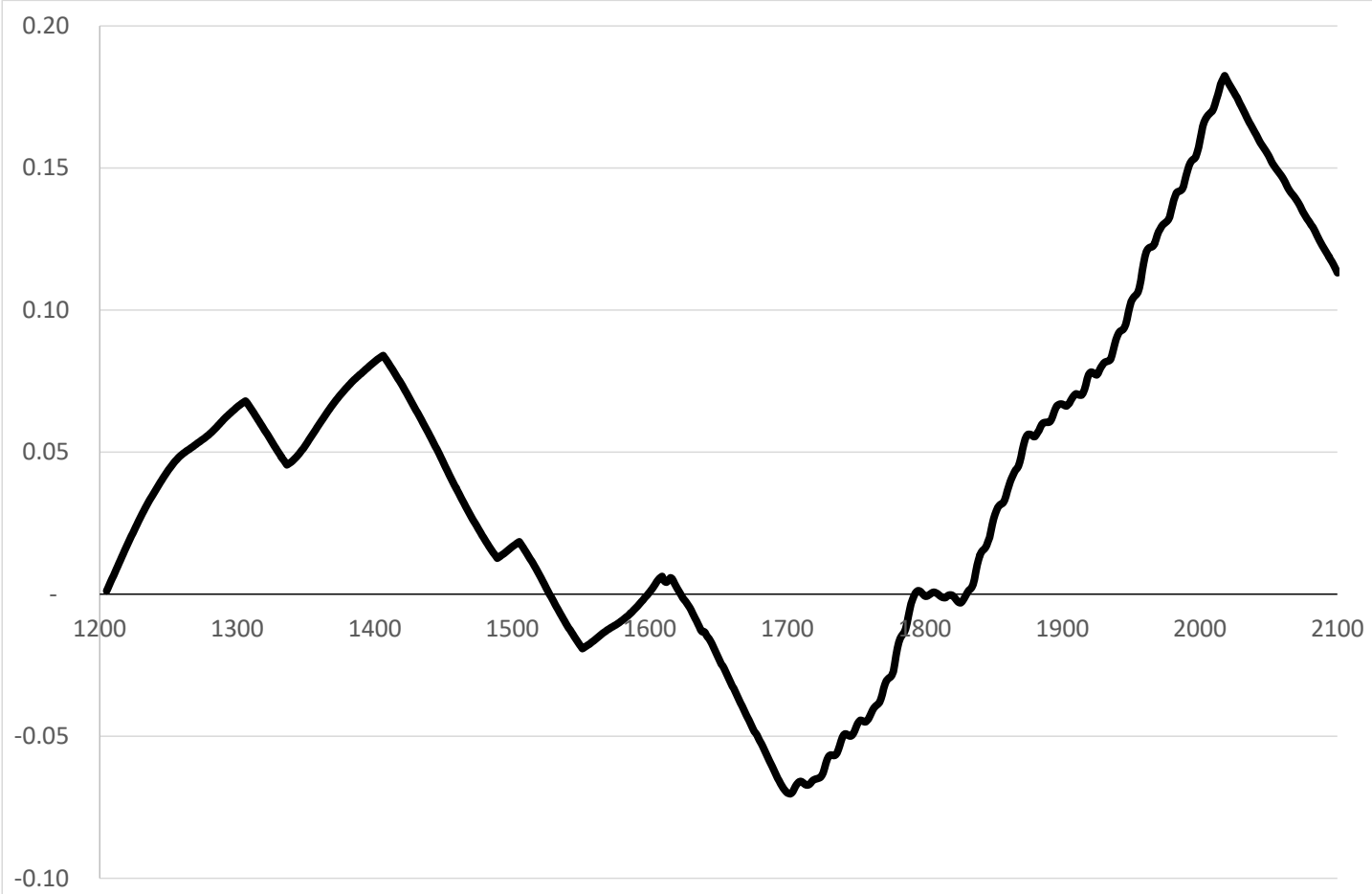

Figure 6. Dataset on Sun-Induced Global Average Temperature Anomaly Component. On x-axis the date in years and on $y$-axis the sun-induced temperature anomaly $T_{-}$sun $\left({ }^{\circ} \mathrm{C}\right)$

It can be noted that the variation due to only sun effects from 1880 to 2010 is about $0.10^{\circ} \mathrm{C}$, which is well in line with the upper side of the range estimated by $\operatorname{IPCC}\left(0.1 \mathrm{~W} / \mathrm{m}^{2} \times 0.8^{\circ} \mathrm{C} /\left(\mathrm{W} / \mathrm{m}^{2}\right)=0.08^{\circ} \mathrm{C}\right)$.

Step 5: From T_sun to Arctic Amplification (delta SIE and delta T1)

Input Data

Input data is the modelled data series T_sun.

Model Description

The coefficients of correlation between T_sun and Arctic Amplification (delta SIE and delta T1) are determined based on the input data reported in Table 2 .

Table 2: Obtained AA Correlation Factors

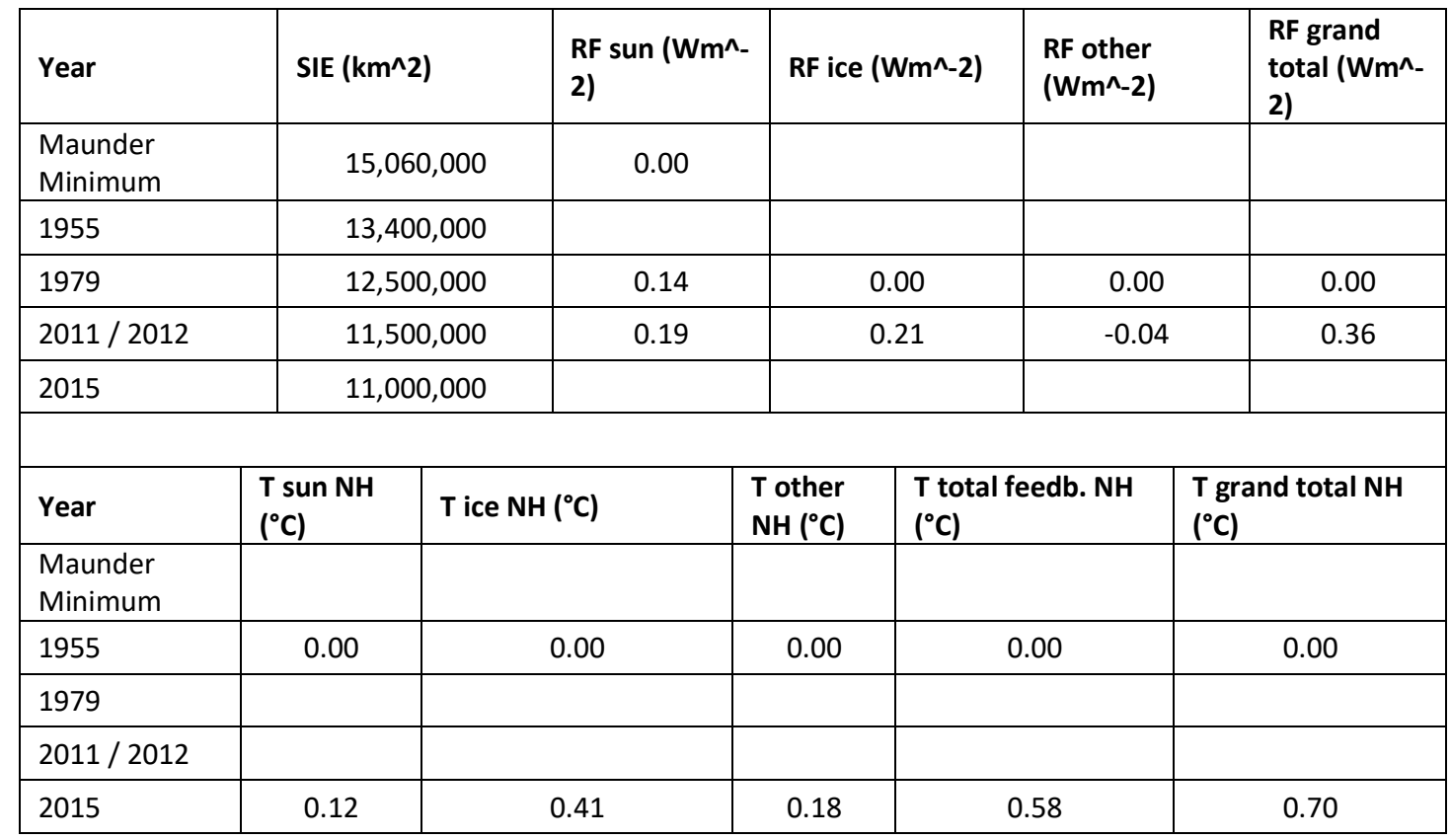




\begin{tabular}{|c|c|c|c|c|c|}
\hline Coefficient & Sun & Ice & Other feedback & $\begin{array}{c}\text { Total } \\
\text { feedback }\end{array}$ & $\begin{array}{l}\text { Grand } \\
\text { total }\end{array}$ \\
\hline $\begin{array}{l}\mathrm{RF} / \mathrm{SIE}\left(\mathrm{Wm}^{\wedge}-2\right. \\
\left./ \mathrm{km}^{\wedge} 2\right)\end{array}$ & & $-2.10 \mathrm{E}-07$ & & & \\
\hline $\mathrm{T} / \mathrm{SIE}\left({ }^{\circ} \mathrm{C} / \mathrm{km}^{\wedge} 2\right)$ & $\begin{array}{c}-4.86 \mathrm{E}- \\
08 \\
\end{array}$ & $-1.70 \mathrm{E}-07$ & $-7.29 E-08$ & $-2.43 \mathrm{E}-07$ & $-2.92 \mathrm{E}-07$ \\
\hline$\lambda(\mathrm{T} / \mathrm{RF})\left({ }^{\circ} \mathrm{C} / \mathrm{Wm}^{\wedge}-2\right)$ & & 0.81 & & & \\
\hline $\begin{array}{l}\text { SIE sensitivity ( } 10^{\wedge} 6 \\
\left.\mathrm{~km} 2 /{ }^{\circ} \mathrm{C} T_{\text {_ }} \text { sun }\right)\end{array}$ & $\begin{array}{c}- \\
20,571,4 \\
29 \\
\end{array}$ & & & & \\
\hline $\begin{array}{l}\mathrm{T} \text { Amplification }\left({ }^{\circ} \mathrm{C}\right. \\
\left.\text { total } /{ }^{\circ} \mathrm{C} \text { sun_forced }\right)\end{array}$ & 6.00 & & & & \\
\hline
\end{tabular}

Table 2 sources (top part):

- SIE extensions are from Laubereau and $I g l e v^{10}$, with the exception of the value for the Maunder Minimum, where it is assumed the SIE corresponded to the entire Arctic Sea area;

- $\quad$ RF_sun values are obtained from the model (Step 2);

- $\quad$ RF ice are obtained for 1979 and 2011 /2012 from Pistone et al. ${ }^{11}$;

- $\quad$ RF grand total is obtained from Temperature (Tokyo Climate Centre ${ }^{21}$ ) and $\lambda=0.8$ (IPCC);

- $\quad$ FR other feedbacks is obtained as difference.

In Table 2 (Centre Part), Temperature anomaly components for the Norther Hemisphere (NH) are obtained applying the percentage of the different types of forcing from Laubereau and Iglev ${ }^{10}$ to the HadCRUT4 ${ }^{20}$ data for the same reference years (1955 and 2015). No figure has been derived from the model, and all values are from external references.

Table 2 (bottom part) reports the correlation factors as obtained from the two previous tables. The factors can be easily obtained dividing the numerator and denominator data difference for the same couple of years. Only factors of interest for the model are reported.

\section{Model Output}

The delta SIE partial variation obtained multiplying the above constant by the T sun values on the entire data series from 1200 to 2100 is obtained.

The global average temperature anomaly $\mathrm{T} 1$ is obtained multiplying the above constants by the $T$ _sun values on the entire data series from 1200 to 2100 .

\section{Step 6: From AMO to delta AASCIC and delta T2}

\section{Input Data}

Data on the yearly AMO index are from the National Ocean and Atmosphere Administration 22 for the years 1856 2019.

Data from 1585 to 1855 are reconstructed by Knudsen et al ${ }^{23}$.

Data from 1200 to 1584 and from 2020 to 2100 are assumed as the average value of the time interval 1585 2019, lacking any literature reference to extend further the data.

\section{Model Description}

According to Li et al. ${ }^{13}$, the variation of AMO index from 1975 to 2012 (increased of 0.417 ) is associated with a decrease of December AASIC of about 1.271 million $\mathrm{km}^{2}$, from a maximum ice extension in 1975 of 2.40 million $\mathrm{km}^{2}$ to a minimum ice extension in 2012 of 1.13 million $\mathrm{km}^{2}$. The data indicate a correlation factor of -3.05 million $\mathrm{km}^{2}$ / delta $\mathrm{AMO}$ index and consequently of $0.74^{\circ} \mathrm{C} /$ delta $\mathrm{AMO}$ index (applying the same $\mathrm{T} \mathrm{NH}$ \& global correlation of $-2.43 \times 10^{\wedge}-7^{\circ} \mathrm{C} / \mathrm{km}^{\wedge} 2 \mathrm{SIE}$ ).

For the correlation, the 11-year average of the AMO Index is multiplied by the above-determined factors to obtain the AASIC and T2 variations.

\section{Model Output}

The delta AASIC variation on the entire data series since 1200 to 2100 is obtained.

The total average temperature anomaly induced by AMO (T2) on the entire data series from 1200 to 2100 is obtained. 
Step 7: Obtaining the global average $\mathrm{T}$ and SIE anomaly

Input Data

Input data are modelled T1, T2, delta SIE_partial and delta AASIC.

Model Description

The results of the model are obtained through the two following equations.

$T(y)=T 1(y)+T 2(y)+K 1$

$\operatorname{SIE}(y)=\Delta \operatorname{SIE} E_{\text {partial }}(y)+\Delta A A S I C(y)+K 2$

Where:

- $\quad \mathrm{T}(\mathrm{y})=\quad$ average global temperature anomaly $\left({ }^{\circ} \mathrm{C}\right)$ in the year $\mathrm{y}$

- $\mathrm{T} 1(\mathrm{y})=\quad$ average global temperature anomaly $\left({ }^{\circ} \mathrm{C}\right)$ due to Arctic Amplification in the yeary

- $\quad \mathrm{T} 2(\mathrm{y})=\quad$ average global temperature anomaly $\left({ }^{\circ} \mathrm{C}\right)$ due to $\mathrm{AMO}$ in the year $\mathrm{y}$

- $\quad \operatorname{SIE}(\mathrm{y})=\quad$ Total SIE $\left(10^{6} \mathrm{~km}^{2}\right)$ in the year $\mathrm{y}$

- $\quad \Delta$ SIE_partial $(y)=\quad \operatorname{SIE}\left(10^{6} \mathrm{~km}^{2}\right)$ anomaly in the year $y$ (due to Arctic Amplification)

- $\quad \triangle A A S I C \_p a r t i a l(y)=\quad$ AASIC $\left(10^{6} \mathrm{~km}^{2}\right)$ anomaly in the year $\mathrm{y}$ (due to AMO)

- $\mathrm{y}=\quad$ Considered year

- $\mathrm{K} 1=\quad$ temperature offset of $-0.25^{\circ} \mathrm{C}$ (arbitrarily set)

- $\mathrm{K} 2=\quad \mathrm{SIE}$ offset of $13.7 \times 10^{6} \mathrm{~km}^{2}$ (arbitrarily set)

Model Output

The total average global temperature anomaly T on the entire data series from 1200 to 2100 is obtained.

\section{Acknowledgements}

I thank Giada Barla, Marco Bogliolo, Andrei Dan Dalmazio and Marco Martinelli for their assistance for revising this article and of the model it describes. All figures have been drawn by the author.

\section{Additional Information}

The Author has no conflict of interest concerning the article and has received no funds from any source for drafting this article.

\section{Availability of materials and data}

Materials, data and associated protocols are available to readers without undue qualifications in material transfer agreements. No restrictions on the availability of materials or information is given. All images are available for reproduction or adaptation without asking Author's permission.

\section{Author contributions}

Marco Morando provided the only contribution to this article. 


\section{References}

${ }^{1}$ Kirkby, J. Cosmic rays and climate. European Organization for Nuclear Research, CERN, Geneva, Switzerland, CERN-PH-EP/2008-005 (2008)

${ }^{2}$ Lean, J., Beer, J. \& Bradley, R. Reconstruction of solar irradiance since 1610: implications for climate change. Geophysical Research Letters (1995)

3 Pangburn, D. Influence of sunspots on global mean temperature. Energy and Environment. https://doi.org/10.1260/0958-305X.25.8.1455 (2014)

${ }^{4}$ Abdussamatov, H. I. Bicentennial decrease of the total solar irradiance leads to unbalanced thermal budget of the earth and the little ice age. Pulkovo Observatory of the RAS (2011)

${ }^{5}$ Shepherd, S. J., Zharkov, S. I. \& Zharkova, V. V. Prediction of solar activity from solar background magnetic field variations in cycles 21-23. The Astrophysical Journal, 795:46 (8pp), 2014 November 1 https://doi.org/10.1088/0004-637X/795/1/46 (2014)

${ }^{6}$ Stocker, T.F. et al. IPCC: climate change 2013: the physical science basis. Contribution of working group I to the fifth assessment report of the intergovernmental panel on climate change. Cambridge University Press, Cambridge, United Kingdom and New York, NY, USA, 1535 pp. (2013)

${ }^{7}$ Nuccitelli, D., Way, R., Painting, R., Church, J., \& Cook, J. Comment on “Ocean heat content and Earth's radiation imbalance. II. Relation to climate shifts". Physics Letters A, 376, 3466-3468 (2012).

${ }^{8}$ NASA Earth Observatory. Retrieved at https://earthobservatory.nasa.gov/features/HeatBucket/heatbucket4.php

9 Lindsey, R. and Dahlman, L. A. Climate Change: Global Temperature. NOAA website, retrievable at https://www.climate.gov/news-features/understanding-climate/climate-change-global-temperature (2020)

10 Laubereau, A. \& Iglev, H. Arctic sea ice and the mean temperature of the northern hemisphere. PhysikDepartment E11, Technische Universität München, James-Franck-Strasse, D-85748, Garching, Germany

11 Pistone, K., Eisenman, I. and Ramanathan V. Observational determination of albedo decrease caused by vanishing Arctic sea ice, edited by Gerald R. North, Texas A\&M University, College Station (2014)

12 Fang, K. et al. Time-varying relationships among oceanic and atmospheric modes: a turning point at around 1940. Quaternary International. (2017)

${ }^{13} \mathrm{Li}$, F. et al. Atlantic Multidecadal Oscillation Modulates the Impacts of Arctic Sea Ice Decline. Geophysical Research Letters (2018)

${ }^{14}$ SILSO data/image, Royal Observatory of Belgium, Brussels. Sunspot Index and Long-term Solar Observations. http://www.sidc.be/silso/datafiles\#total (2019)

${ }^{15}$ Solanki, S. K., Usoskin, I. G., Kromer, B., Schüssler, M., Beer, J. Grand minima and maxima of solar activity: new observational constraints 2004, Astronomy \& Astrophysics (2007).

${ }^{16}$ Eddy, J. A. The Maunder Minimum, Science, New Series, Vol. 192, No. 4245, pp. 1189-1202 (1976)

17 NASA. Solar Radiation and Climate Experiment (SORCE). Retrievable at http://lasp.colorado.edu/home/sorce/data/tsi-data/\#historical_TSI

${ }^{18}$ NASA. SORCE's Solar Spectral Surprise. Archived from the original on 22 November 2016.

https://www.nasa.gov/topics/solarsystem/features/solarcyclesorce.html 
19 NASA. Archived from the original on 21 April 2014.

https://web.archive.org/web/20140421050855/http://science-edu.larc.nasa.gov/energy budget/

${ }^{20}$ HadCRUT4 Northern Hemisphere Temperature data. Archived from the original on 29 March 2021. https://crudata.uea.ac.uk/cru/data/temperature/

${ }^{21}$ Tokyo Climate Centre. http://ds.data.jma.go.jp/tcc/tcc/products/gwp/temp/list/mon wld.html (2019)

${ }^{22}$ National Ocean and Atmosphere Administration (NOAA). Retrievable at https://www.esrl.noaa.gov/psd/data/correlation/amon.us.long.data (2019)

${ }^{23}$ Knudsen, M. F., Jacobsen, B. H., Seidenktantz, M.-S. and Olsen, J. Evidence for External forcing of the Atlantic Multidecadal Oscillation since termination of the little ice age. Nature Communications (2013)

${ }^{24}$ Spencer, R. 2000 years of Global Temperatures: The 2007-2008 Global cooling event. www.drroyspencer.com/ (2007)

${ }^{25}$ Lockwood, M., Owens, M., Hawkins, E., Jones, G. S. \& Usoskin, I. The Maunder minimum and the little ice age: an update from recent reconstructions and climate simulations, A\&G, Astronomy and Geophysics (2017)

26 Met Hadley Centre. Observations datasets. https://www.metoffice.gov.uk/hadobs/hadsst3/diagrams.html (2019)

${ }^{27}$ ACSYS, AARI sea ice data. Arctic Climate System Study (ACSYS). The ACSYS Historical Ice Chart Archive (15532002) published on CD-ROM (2003).

${ }^{28}$ Alekseev, G., Glok, N., and Smirnov, A. On assessment of the relationship between changes of sea ice extent and climate in the Arctic. International Journal of Climatology, 36, 3407-3412. doi:10.1002/joc.4550 (2016) 